\title{
¿Y antes de Fauchard qué? La odontología en las cavernas, los templos, los hospitales y las universidades
}

\author{
And what was there before Fauchard? Dentistry in caverns, \\ temples, hospitals and universities
}

Ramírez Skinner $\mathrm{H}^{1}$

\begin{abstract}
RESUMEN
Este trabajo muestra los orígenes de la odontología entre los primitivos habitantes del planeta, entre los médicos de la Antigüedad, el Renacimiento y la Edad Media hasta los tiempos modernos y la instauración del concepto de hospital clínico universitario. Sostiene que la práctica de la odontología es por definición un acto médico que tiene por objeto al ser humano en la sociedad y la salud a restablecer como bien único e indivisible, siendo ambos conceptos los que delimitan y enmarcan toda la práctica médica. La odontología nace junto con el ser humano, junto con el enfermar, el envejecer y el morir.
\end{abstract}

Rev. Clin. Periodoncia Implantol. Rehabil. Oral Vol. 5(1); 29-39, 2012.

Palabras clave: Historia de la medicina, historia de la odontología, acto médico, educación del cirujano dentista.

\section{ABSTRACT}

This paper shows the origin of dentistry among the primitive inhabitants of the planet, the physicians of the Antiquity, Renaissance and Middle Ages up to the modern times and the establishment of the concept of university clinical hospital. It endorses the practice of dentistry by definition as a medical act that has the human being in the society as the object of the act itself, and the health to restore as the one and indivisible good to enhance. Both concepts are the limits and natural frame of all the medical practice. Dentistry was born with the human being, together with getting sick, ageing and dying.

Rev. Clin. Periodoncia Implantol. Rehabil. Oral Vol. 5(1); 29-39, 2012.

Key words: History of medicine, history of dentistry, medical act, education for the surgeon dentist.

\section{INTRODUCCIÓN}

La práctica y enseñanza de la odontología ha estado en manos médicas desde que la especie humana se organiza en el planeta. Este reporte pretende mostrar los orígenes de la atención de la patología oral desde los primitivos, la interpretación mágico religiosa de la enfermedad, la medicina hipocrática, el renacimiento del clasicismo y la instauración de la noción de hospital clínico universitario en las escuelas europeas del siglo XIX. En todo este tiempo siempre hubo médicos dedicados exclusivamente al arte dental.

Desde la antigüedad, las acciones odonto-estomatológicas han sido consideradas como una parte inherente del acto médico. El acto médico es un acto ético para el ser humano en la polis. El hombre como objeto material y la salud a restablecer como bien particular definen la naturaleza y los límites de la práctica médica ${ }^{1}$. El campo de responsabilidad es la salud del paciente, función que el profesional cumple por medio de la toma de decisiones en forma integral y autónoma. Parece poco razonable que todavía algunos médicos no distingan en la práctica odontológica una conducta que apunta al bien total del hombre. Nosotros entregamos los medios adecuados para ir en busca de dicho fin, con la prudencia adquirida mediante transmisión directa por un maestro al lado del paciente.

En este punto se hace perentorio aclarar que cuando sostengo la odontología en manos médicas no cedo ni un milímetro en la autonomía de la profesión en el mundo de hoy, que distingue dos gremios con sus ámbitos propios, definidos con claridad y con un área común explorada por diferentes métodos pedagógicos. Se trata, justamente, de entregar a los cirujanos dentistas todas las herramientas para ejercer la odontoestomatología, tal como señala el artículo 115 del Código Sanitario chileno $^{2}$.

Entiendo y he sido testigo de las resistencias, divisiones y problemas que ha creado, no sólo en nuestro medio, el uso de los términos estomatología y odontología. En este trabajo los uso como sinónimos (aunque etimológicamente no lo son), para referirme al ámbito de ejercicio del cirujano dentista.

La siguiente es una descripción resumida de la labor de los que trataron las enfermedades orales y dentales desde que la raza humana habita el planeta. Aunque no pretende ceñirse al rigor de la investigación historiográfica, persigue relatar lo que probablemente fue la práctica del arte dental entre los médicos que antecedieron a Pierre Fauchard ${ }^{3}$. La odontología no nace con el edicto de Luis XIV en 1699 que crea el gremio de los cirujanos dentistas. Nació con la humanidad, con el enfermar y el morir. No he encontrado muchas publicaciones sobre esto en Chile, pero probablemente mejores búsquedas podrán dar más luces sobre nuestro pasado histórico.

\footnotetext{
${ }^{1}$ Besio M. Sobre el acto médico. Curso Fundamentos Filosóficos de la Medicina. Pontificia Universidad Católica de Chile. Santiago, 2008.

2 "Los cirujanos dentistas sólo podrán prestar atenciones odonto-estomatológicas. Podrán, asimismo, adquirir o prescribir los medicamentos necesarios para dichos fines, de acuerdo al reglamento que dicte el Director General de Salud" (N. del A.).

${ }^{3}$ Pierre Fauchard (1678-1761) se formó como cirujano militar y se instaló en París hasta su muerte. Resumió el conocimiento sobre odontología en occidente, sintetizando, unificando, ordenando y también aportando nuevos aspectos, sin temor a perder el secreto de su arte, cosa muy temida en la época (N. del A.).
}

1. Cirujano Dentista. Universidad de Chile. Especialista en Cirugía Maxilofacial Conaceo 2000. Subespecialista en Manejo del Dolor Universidad de Chile. Profesor Asistente, Facultad de Medicina, Pontificia Universidad Católica de Chile. Chile. 


\section{ODONTOLOGÍA EN LA PALEOPATOLOGÍA}

Hay rastros de patología dental y ósea en animales muy antiguos. Las enfermedades precedieron a los encargados de curarlas. El estudio de esqueletos y utensilios permitió a Marc Armand Ruffer (1859-1917) ${ }^{4}$ acuñar el término paleopatología durante el siglo XIX. Registros en huesos animales mostraban el primer callo óseo exuberante en un reptil del período Pérmico durante el Paleozoico ${ }^{5}$. Otros hallazgos de patología local incluían osteomielitis, focos intraóseos infecciosos, engrosamientos osteogénicos del periostio, artrosis; las malformaciones, descalcificaciones y condensaciones óseas podían considerarse como manifestación secundaria de enfermedades generales. Hay registros de esqueletos de dinosaurios y plesiosaurios que tienen artropatías, fracturas, osteomielitis y caries dentales. El sistema masticatorio de los primitivos también mostraba evidencia de enfermedad periodontal y otras lesiones óseas.

El hombre de Neanderthal ${ }^{6}$ se extinguió por la competencia con los homo sapiens ya que éstos estaban bien adaptados a las condiciones de glaciación. El cráneo de Chapélle-Aux-Saints en Francia está bien conservado y los maxilares muestran la condición parcialmente desdentada original de este representante Neanderthal. La pérdida de los dientes al parecer tuvo un curso favorable en este "paciente" ya que los rebordes óseos residuales aparecen perfectamente remodelados por un proceso normal post pérdida dental. El aparato masticatorio permite deducir importantes detalles del sistema de alimentación y modo de vida del individuo estudiado.

En el período Neolítico (10.000-7.000 a.C.) el humano cambia su modo de conseguir alimentos y comienza a cultivarlos. Es muy probable, aunque no hay evidencia, que las plantas ya entregaran a sus primitivos cultivadores el secreto de sus propiedades medicinales. Al desarrollar los instrumentos, el hombre comienza con las maniobras quirúrgicas, tal como muestran los cráneos neolíticos con trepanaciones ${ }^{7}$.

El mundo sobrenatural era inmanente en el imaginario del humano primitivo y por ello, religión, magia y medicina constituían una unidad inseparable. La mayor parte de los estados patológicos tenían su origen en espíritus y fuerzas maléficas, las cuales requerían de la intervención del médico-sacerdote o chamán ${ }^{8}$. Tanto el paciente como el médico primitivos estaban condicionados para interpretar los fenómenos, incluyendo las enfermedades, como una consecuencia de la acción de los espíritus malignos per se, o proyectados sobre la persona enferma por la acción maléfica de un brujo. De igual forma, la curación o sanación tenía lugar por la acción del curandero como un intercesor ante el mundo espiritual.

\section{ODONTOLOGÍA EN LA MEDICINA MEDITERRÁNEA}

El médico se constituyó en oficiante de un rito consagratorio que se extendió por un lapso aproximado de cuatro mil años entre los albores de la cultura urbana de la cuenca mediterránea hasta la creación de la escuela hipocrática ${ }^{9}$. El sacerdote-médico tiene sus predecesores en adivinos y exorcistas babilonios, magos y curanderos asirios, sacerdotes egipcios y rabinos judíos.

\section{MESOPOTAMIA}

El oficio de médico era peligroso en las culturas que habitaron entre el Tigris y el Éufrates. El código de Hamurabi de fines del s. XIX a.C. contiene ejemplos de numerosas regulaciones, entre las cuales estaban las derivadas del ejercicio profesional.

El museo británico en Londres tiene una de las más antiguas tablillas de arcilla cocida grabada con los caracteres cuneiformes asirios pertenecientes a la biblioteca del rey Assurbanipal, en Nínive, Babilonia; esta tablilla hace referencia al Gusano de los dientes, encarnación del demonio Tiament, tal vez uno de los primeros agentes etiológicos descritos en patología oral. En el templo de Ningual cerca de Ur, Babilonia se encontró un juego de instrumentos de higiene dental datados cerca de 3000 a.C. lo cual indica que el gusano de los dientes no sólo es un concepto mágico. Usaron variados remedios para este mal dentario: cerveza, aceite, plantas especiales, masajes, métodos físicos y cirugía.

El estado de los dientes se usaba a veces para determinar el origen y el curso de una enfermedad. El rechinar de los dientes era considerado peligroso por lo que existía un ritual para sanar esta condición. La colección Kuyunjik (820-750 a.C.) contiene el relato atribuido al médicoodontólogo Arad Nanai con la recomendación de extraer los dientes de un hijo del monarca por considerarlos la causa de una enfermedad a distancia.

\section{EGIPTO}

En Egipto, la sociedad estaba jerarquizada en castas hereditarias en que las funciones sociales, las profesiones y los oficios se enseñaban directamente de padres a hijos y transmitidos como un bien familiar. La principal clase era la dirigente formada por sacerdotes (dentro de los cuales estaban los médicos) y los escribas que manejaban la escritura, el cálculo y la administración.

En el siglo II d.C. San Clemente de Alejandría, patriarca de la Iglesia Católica primitiva habla de los 42 libros sagrados que el dios egipcio Thoth ${ }^{10}$ había dado a la humanidad como fuente de todos los saberes. Se trata de la colección hermética que contiene seis libros médicos, siendo el papiro de Ebers el cuarto. Aquí se pueden encontrar hallazgos de caries, atriciones, periodontopatías, quistes, infección ósea odontogénica y fracturas. Contiene varios remedios para afirmar los dientes, para curar la destrucción de la sangre dental, para lo que corroe la encía, para el crecimiento de la purulencia (parulis), la ulceración y el fortalecimiento de ésta. La cirugía oral era de uso común pero no practicaban la extracción dental porque muchos maxilares encontrados muestran enfermedad periodontal avanzada con dentaduras completas. El papiro de Edwin Smith contiene la descripción que luego usa Hipócrates y posteriormente divulga Celso para la luxación de la mandíbula y que es idéntica a la que se usa actualmente ${ }^{11}$.

El tratamiento de las fracturas y trepanaciones de los maxilares requería de un instrumental quirúrgico especializado, además de un conocimiento médico orientado a suprimir las causas. Se ha encontrado cráneos que muestran severas atriciones de los molares debido a la dieta con elementos abrasivos como arena de las piedras de los molinos. Muchos de ellos tienen grandes pérdidas de hueso alveolar, con abscesos en su interior y evidencia de las trepanaciones hechas para drenar dichas colecciones purulentas. El papiro de Edwin Smith cita además otras operaciones sobre los maxilares, perforaciones de cigoma y laceraciones de los labios.

Los rudimentos de férulas se reducían a unas amarras de los dientes con alambre de oro y no hay evidencia de prótesis dentales, lo cual es difícil de aceptar considerando la habilidad artesanal de los egipcios y la importancia de la belleza en la sociedad. En 1862 Gaillardot realizó excavaciones cerca de una tumba en Sidón (Fenicia, actual Líbano) donde encontró una prótesis dental del año 400 a.C la cual consistía en cuatro dientes inferiores naturales amarrados por medio de alambre de oro a dos dientes artificiales tallados en marfil

\footnotetext{
${ }^{4}$ Laín Entralgo P. Op. Cit.

${ }^{5}$ Comenzó hace 542 millones de años y terminó hace 251 millones de años. (N. del A.).

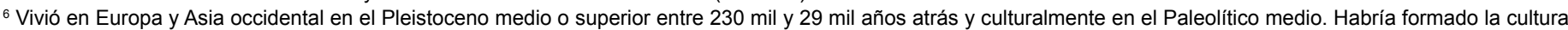
musteriense en lberia hace 600 mil años. (N. del A.).

${ }^{7}$ Lyons A. Op. Cit.

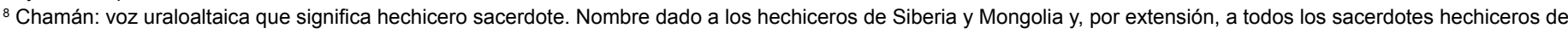
cualquier culto animista. (N. del A.).

${ }^{9}$ Febres Cordero F. Op. Cit.

${ }^{10}$ Posteriormente identificado con el dios griego Hermes, el Mercurio latino. (N. del A.).

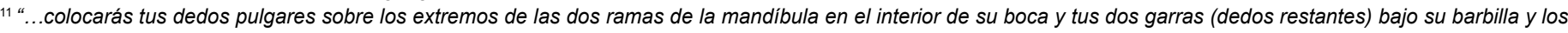
empujarás hacia abajo y atrás para que vuelva a su lugar". (Ring M. Op. Cit).
} 
para reemplazo de dos incisivos perdidos. Poco después se encontró una mandíbula con dentadura casi completa y afectada de una severa enfermedad periodontal, la cual tiene una amarra con alambre de oro en los dientes inferiores a la manera de una férula.

En el imperio antiguo hay registro de al menos tres casos de profesionales que tienen doble título, sunn: médico e ibeh: dentista. Howi fue uno de ellos y oficiaba para las enfermedades de la boca y como guardián del ano. Hesi-Re era jefe de la escuela de médicos de la corte en tiempos de Zoser III (2780-2720 a.C.), era especialista en enfermedades de los dientes y gozaba de gran reputación y respeto en su época. Tanto la naturaleza como el número de las operaciones a realizar hacen pensar que la práctica odontológica estaba en manos de los médicos. Heródoto (484-430 a.C.) enfatizó el alto grado de especialización de los egipcios, distinguiendo entre ellos a ginecólogos, oftalmólogos, odontoestomatólogos y colo-proctólogos. El personal paramédico estaba constituido por farmacéuticos, enfermeros, comadronas, fisioterapeutas y colocadores de vendajes.

\section{ISRAEL}

La práctica odontológica específica estaba en manos de médicos levitas (rophe) o de cirujanos (uman) según el caso y también según la clase social del paciente. Hay dos libros talmúdicos: el de Jerusalem y el de Babilonia, este último mucho más largo y ambos escritos hacia fines del s. VI d.C. La regla talmúdica de prohibición de trabajar en Sabath se hacía aplicable incluso a una mujer que portara un diente postizo, porque si al salir de su casa éste se caía, ella debería recogerlo y eso era considerado una forma de trabajo. En otro párrafo del libro de Babilonia se mencionaba a una mujer cuyo novio la rechazó en matrimonio luego que ella sufriera la fractura de un diente artificial y volvió a aceptarla luego que el rabino Ismael le fabricó un diente de oro.

El Talmud contiene recomendaciones profilácticas odontológicas: demasiado vinagre es malo para los dientes; su uso moderado alivia las heridas de las encías; frutos ácidos para el dolor de muelas; puerros y uvas verdes deterioran los dientes. La práctica médica en general y las extracciones dentales en particular eran temidas por los antiguos judíos ${ }^{12}$. Los dolores de muelas eran considerados como enfermedades internas y bajo la responsabilidad, por lo tanto, de los médicos. Los hebreos concedieron un gran valor a los dientes sanos, siendo su pérdida una indicación de enfermedad y debilidad $^{13}$

\section{GRECIA DESDE LOS TEMPLOS DE ASCLEPIO A LA MEDICINA HIPOCRÁTICA}

La mentalidad mágico-religiosa coexistió con el empirismo secular en la mentalidad médica griega. El culto a Asclepio ${ }^{14}$ vino de aquel en que se veneraba a dioses antiguos de la tierra y del mundo subterráneo, personificados muchas veces por animales como serpientes y topos. Los templos de la salud de Asclepio (asclepeion) surgieron hacia el siglo VI a.C., en el mundo helénico. Cada templo era un gran recinto con un templo central, una estatua del dios y algunos de sus familiares, en las entradas había inscripciones con testimonios de curas milagrosas y agradecimientos. El tholos era una construcción circular que contenía el agua purificadora y el abaton era el lugar donde se producía la curación del fiel paciente durante el sueño, luego de ser visitado por el dios. El templo de Esculapio en Epidauro tenía gimnasio, teatro y un estadio para influir en el ánimo de la gente. Algunos también tenían alojamientos temporales.

El enfermo ingresaba al templo, ayunaba previamente, recibía un baño purificador y hacía una ofrenda de gratitud y, así, se encontraba en condiciones de comenzar la incubación, período en el cual se le inducía con algunas plantas un estado alterado de la conciencia. El dios aparecía en los sueños por sí mismo o indirectamente a través de animales sagrados como serpiente, perro, ganso, aplicaba las manos al soñador, un medicamento o una intervención quirúrgica y actuaba por vía del sacerdote-oficiante el cual usaba métodos de tratamiento similares a los del médico laico. Cuando el paciente era sanado, dejaba una tableta votiva inscrita con sus agradecimientos y con la forma del órgano curado; se han encontrado tabletas con forma de mandíbula y dientes lo que indica que también se curaban enfermedades dentales.

Los siglos que transcurrieron entre el período minoico y los filósofos presocráticos fueron una constante liberación del concepto mágico-religioso y progresivo predominio racional. La creciente importancia que los griegos dieron a la salud fue la causa de la elevación social de los sanadores. Los ciudadanos más ricos pagaban a los prácticos más expertos, los cuales cobraban honorarios acordes con la posición social del paciente. El grueso pueblo era atendido en los templos de Asclepio o por los ayudantes y esclavos de los médicos.

No existían especialistas y todo acto curativo era una variante del arte único de curar. Los médicos realizaban las operaciones y los tratamientos de las enfermedades de la boca y los dientes. Aprendieron de los etruscos la ligadura de los dientes con hilos de oro, drenaban abscesos y reducían la luxación de mandíbula como hacían los egipcios. Eran hábiles tratando fracturas y lesiones óseas, practicaban la reducción incluso con instrumentos, usaban el cauterio para heridas, infecciones y tumores. Conocían los analgésicos como el opio y la mandrágora.

Hipócrates habría nacido hacia el 460 a.C. en la isla de Cos y muerto en Tesalónica en 377 a.C. Vivió la mayor parte del tiempo en Cos, donde se educó y luego dirigió una prestigiosa escuela médica. Sus obras están reunidas bajo el denominado Corpus Hippocraticum. Los tratados más completos, claros, consistentes y pragmáticos de la colección son los de cirugía y dicen: "quien desee practicar la cirugía debe ir a la guerra".

Las descripciones de los métodos para corregir fracturas y todo tipo de dislocaciones, heridas de la cabeza, cara, boca y dientes son abundantes y detalladas. Tal como se considera a Hipócrates el padre de la medicina, debe considerársele también como el abuelo del arte dental, ya que acuñó el término "muela del juicio" para los terceros molares, describió el manejo de la infección odontogénica y aconsejó los tratamientos específicos para las odontalgias ${ }^{15}$.

Las hemorragias se trataban con compresión, lavados o tratamiento postural. De los escritos contenidos en el Corpus Hippocraticum, uno de ellos, Sobre los dientes habla en detalle sobre la dentición, la formación de los dientes y el recambio dentario. Las extracciones dentarias se consideraban peligrosas, pero los instrumentos para ello se llamaron odontagra, el cual se usaba sólo cuando los dientes estaban flojos. Una frase que resume el pensamiento quirúrgico del sabio de Cos es la siguiente: "Lo que no se cura con medicamentos, se cura con el cuchillo; lo que el cuchillo no cura, lo hace el fuego y lo que el fuego no puede curar, se considera incurable".

\footnotetext{
12 "No adquieras el hábito de tomar medicinas. No las tomes por largas dosis. Evita que te extraigan un diente". (Ring M. Op. Cit).

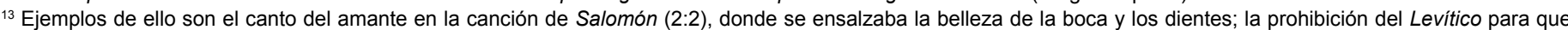

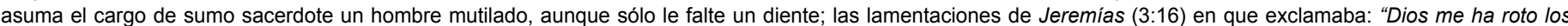

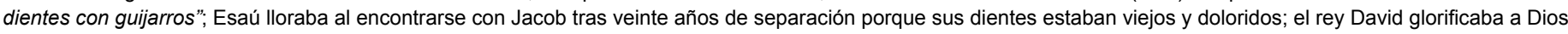

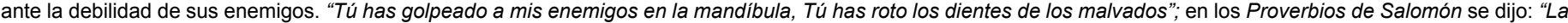
confianza en un traidor en tiempos de peligro es como confiar en un diente podrido". (Lyons A. Op. Cit).

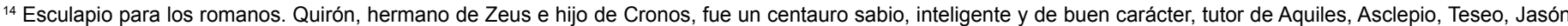

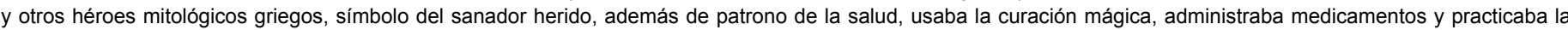

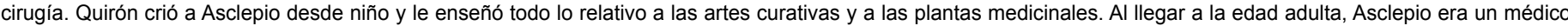

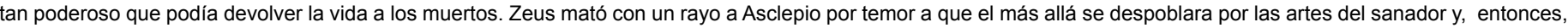
fue convertido en un dios. (N. del A.).

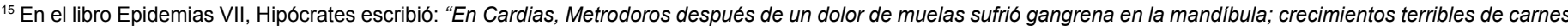
en sus encías; moderada cantidad de pus; las muelas y hasta la mandíbula se le cayeron". (Hipócrates. Tratados. Op. Cit).
} 


\section{ALEJANDRÍA Y LA SEPARACIÓN ENTRE MÉDICOS Y CIRUJANOS}

Las diferentes escuelas o sectas médicas asentadas mayoritariamente en Alejandría constituyeron la base del pensamiento médico después de la muerte de Hipócrates. La terapéutica avanzó lentamente en el período descrito, con la excepción quizás de la cirugía, bajo cuyo amparo estaba la estomatología. Gracias a los avances en la disección anatómica efectuados en Alejandría, la cirugía se desarrolló con mayor rapidez que el resto de la medicina, especialmente si consideramos que para algunas escuelas la disección cadavérica era una práctica prohibida por impura. De aquí en adelante y durante varios siglos se produjo una separación entre médicos y cirujanos, siendo los últimos considerados de un rango inferior. Entre ellos se cuenta a los cultores de la terapéutica odontológica, los cuales en su mayoría eran cirujanos, aunque también los hubo entre los médicos, tal como muestra la historiografía posterior ${ }^{16}$

La información disponible sobre medicina alejandrina y romana se debe a dos enciclopedistas, Aulo Cornelio Celso y Plinio el Viejo ambos del s. I d.C. También Galeno puede considerarse un ejemplo de la medicina y cirugía alejandrinas.

Celso (ca. 1437) fue un patricio romano que compiló los conocimientos de la época: agricultura, derecho, arte militar, filosofía, retórica y medicina. Su obra De Medicina compuesta de ocho libros, escrita en griego, trata de materias variadas como historia de la medicina, prevención en salud, enfermedades de casi todos los órganos, cirugía y terapéutica. Su descripción rubor et tumor cum calor et dolor es todavía la característica enseñada para la inflamación. La obra de Celso provee de información sobre instrumental quirúrgico usado en cirugía dental y de los maxilares, el tenaculum era un instrumento especial para extraer las raíces de los dientes. Detallaba la reducción de la luxación de la mandíbula tal como hacían los egipcios y según aparece en el papiro de Edwin Smith. El capítulo 9 del libro VI trata exclusivamente del dolor de muelas mediante gran variedad de cataplasmas calientes, enjuagues bucales, aplicaciones de vapor, purgas y laxantes.

Cayo Plinio (23-79 d.C.) recopiló información sobre historia, física, química, biología, geografía, nutrición, filosofía, magia, folklore, plantas y medicina. Propuso una cura mágica para el dolor de muelas que consistía en encontrar una rana a la luz de la luna llena, mantener su boca abierta, escupirle dentro y enunciar la siguiente fórmula: "Rana, ve y llévate mi dolor de muelas contigo".

Claudio Galeno nació hacia el año 129 d.C. en el seno de una familia griega rica, de elevada cultura. Aprendió la importancia de la anatomía, la experiencia clínica y las doctrinas hipocráticas. A los 20 años fue therapeutes en el asclepeion de Pérgamo. Fue influenciado por la importancia que a la anatomía se le confería en ciudades como Esmirna, Corinto y Alejandría. Trabajó como médico de los gladiadores, adquiriendo grandes habilidades y experiencia como cirujano. Su obra Sobre la utilidad de las partes del cuerpo, contiene un tratado integrado de anatomía y fisiología. Su libro XI: La Cara es sorprendente por el fino detalle y la gran intuición que demuestra Galeno en estomatología, describiendo, entre otros acápites, el nervio trigémino y los músculos masticadores. En su obra Sobre la Higiene, Galeno habló del verdadero origen que a su juicio tiene la infección de la boca, demostrando además que las enfermedades orales eran tratadas por los médicos ${ }^{17}$.

\section{ODONTOLOGÍA ENTRE LOS MÉDICOS ÁRABES}

Las continuas invasiones bárbaras, la inestabilidad política, las epidemias y otras catástrofes fueron las principales causas de la pérdida del legado helenístico y romano en Europa. La nueva religión islámica fue, a partir del siglo VII, un impulso para la conservación de los conocimientos clásicos y su posterior recuperación por el mundo europeo.

El conjunto de la literatura árabe dedicada a la salud y la curación es muy extenso, pero no posee textos específicos dedicados a odontología. Uno de los más completos es el Firdaus Al Hikma escrito hacia 850 por Alí ibn Sahl Rabban at Tabari, cuyo nombre en español es Paraíso de la Sabiduría, el cual contiene algunos temas estomatológicos como el origen de los dientes, el tratamiento del aliento fétido y varias recetas de dentífricos y remedios para la boca.

Uno de los médicos más destacados fue el persa Razes (850932). Su obra Kitab Al Hawi o Liber Continens (Recopilación) contiene una síntesis de los conocimientos médicos y quirúrgicos de su época (del siglo VII al siglo X) donde se puede encontrar abundante material referente a clínica y terapéutica odontológica ${ }^{18}$.

Alí Abbas (muerto en 994) escribió textos quirúrgicos de gran valor que fueron adoptados fielmente en Europa por los cristianos. Uno de los capítulos de su obra Libro Real está dedicado a las enfermedades de los dientes, donde recomienda la cauterización y se manifiesta partidario de las extracciones.

Abulcasís (936-1013) nació en Córdoba y su obra AlTasrif (El Método) es una enciclopedia médico-quirúrgica con una lista de cientos de instrumentos quirúrgicos y su modo de empleo. Una parte de ésta fue traducida posteriormente como De Chirurgia y le proporcionó una fama enorme como el mejor cirujano oral de su tiempo ${ }^{19}$

El más grande de los médicos árabes por su influjo, sólo comparable al de Galeno tanto en el mundo islámico como cristiano, fue Avicena (980-1037). Nació cerca de Bokhara, en Persia y fue un niño prodigio que a los diez años explicaba el Corán. Los aportes originales de Avicena fueron escasos en materia quirúrgica y médica estomatológica: recomendaba la higiene oral prolija, el uso de los dentífricos, trataba las afecciones de la erupción, fumigaba diferentes sustancias para el dolor de muelas, desgastaba los dientes alargados, usaba el arsénico en las fístulas y úlceras fétidas de la mucosa oral y describió la manera correcta de tratar las fracturas de la mandíbula.

\section{LA MEDICINAAL AMPARO DE LOS HOSPITALES Y UNIVERSIDADES}

Tras la caída de Roma, el legado médico griego y oriental se cobijó en los monasterios católicos donde funcionaron instituciones de caridad para el cuidado de los enfermos.

Pablo de Egina (625-690) fue el último de los eclécticos griegos que escribió sobre odontología. Su obra Epitome es una compilación de los escritos antiguos. El capítulo Sobre afecciones de la boca distingue entre parulis inflamatorio y tumoral y describe cómo controlar ambos tipos. Explicó con coherencia detalles sobre la dentición, el recambio, las extracciones y la higiene oral. Con Pablo de Egina se acabaron los relatos sobre prótesis funcionales o estéticas,

\footnotetext{
${ }^{16}$ García Palao A. Óp. cit.

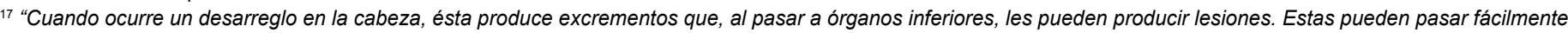

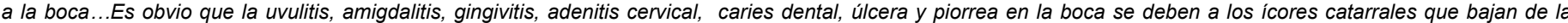

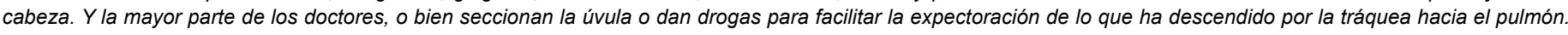

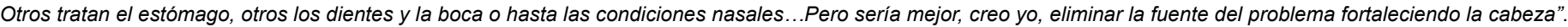
(Tallmadge M. Op. Cit).

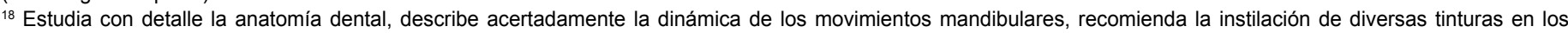

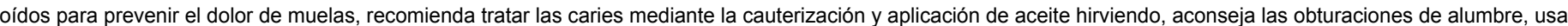

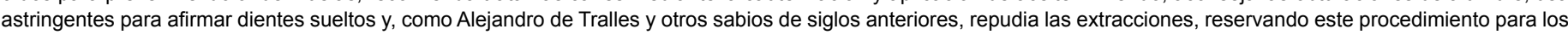
casos en que los dientes son previamente aflojados con diversas sustancias. (Ring M. Op. Cit).

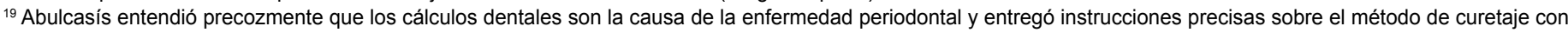

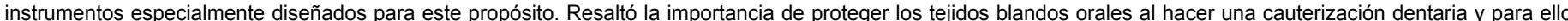

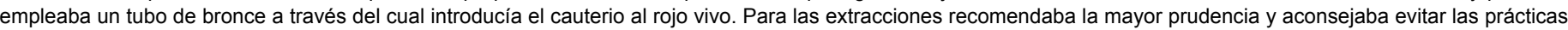

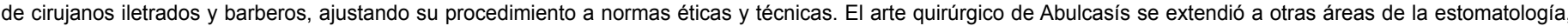

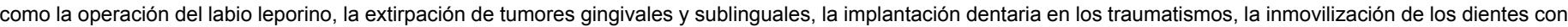

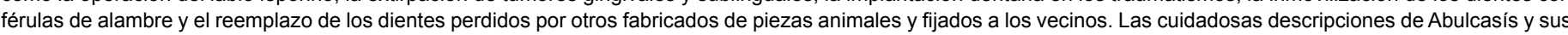


probablemente por el desprecio que la mente cristiana y monacal sentía por el cuerpo y su embellecimiento. Quedó un predominio absoluto de los métodos herbolarios para las odontalgias, el rechazo de los médicos a la cirugía y la práctica de ésta por barberos y ambulantes sin estudios.

Este período de oscurecimiento duraría 700 años hasta el Renacimiento y, poco antes, hasta el florecimiento de la escuela de Salerno cerca de Nápoles hacia el s. X. Aquí nació una nueva escuela que hace propios el legado griego, judío, árabe y latino. La antigua concepción hipocrática y galénica que consideraba a la práctica quirúrgica como un método más de curación, sería desplazada por la creencia en la impureza de tocar o cortar el cuerpo humano y, así, se promulga en 1163 el Edicto del Concilio de Tours $^{20}$ que señala como impropio del quehacer eclesiástico el practicar la cirugía, derramar sangre es incompatible con los santos oficios del clero, "ecclesia abhorret a sanguine" y el arte de la curación mediante la cirugía queda en manos de prácticos casi iletrados por siglos.

Más que en los monasterios benedictinos o en las escuelas agregadas al lado de las catedrales del Sacro Imperio Romano de Carlomagno, la enseñanza formal de la medicina se estableció en las recién creadas universidades de Salerno, Montpellier, París, Bolonia, Padua, Nápoles y otras. La medicina monástica fue declinando paulatinamente y hacia los siglos XII y XIII se transfirió la propiedad de los grandes hospitales de las iglesias a los municipios. Se fundaron algunos famosos como el Hotel Dieu en París, el Santo Spirito en Roma y los de Saint Thomas y Saint Bartholomew en Inglaterra.

Con el tiempo se crearon dos tipos de cirujanos: el de toga larga, que había estudiado en latín, llamado por esto latinista; el de toga corta, cirujano-barbero que debía examinarse con el primero para ejercer y que por no saber latín se llamaba romancista. Con frecuencia se asociaron ambas categorías de prácticos en gremios comunes, pero con el tiempo fueron creando agrupaciones independientes.

Mientras los médicos, a menudo judíos doctos en medicina árabe, atendían a los nobles, alto clero y ricos burgueses, el pueblo se veía obligado a confiar en curanderos, barberos y flebótomos. A partir de ahora, la práctica quirúrgica (que casi siempre incluyó a la odontología) no podría ceder ya más terreno a la ignorancia y a los prácticos iletrados, porque ya no era posible caer aún más en la superstición y en el inmovilismo intelectual. Por otro lado, la anatomía basada en la disección de cadáveres humanos, largamente prohibida, comenzó lentamente a entrar en vigencia, al principio con fines legales y luego para la búsqueda de las causas de enfermedad.

\section{PRÁCTICA Y ENSEÑANZA DE LA ODONTOLOGÍA DURANTE EL RENACIMIENTO}

El Renacimiento trajo consigo la existencia de los llamados médicos humanistas, aquellos que, influidos tanto por las ciencias, la física y la astronomía como por la alquimia, la magia y la astrología, fueron constituyendo un núcleo de pensamiento abierto y libertario, el cual dejó atrás a los fundamentos del escolasticismo medieval, dando paso a un resurgimiento del empirismo hipocrático y luego a un franco experimentalismo científico.

Theophrastus Bombastus von Hohenheim, mejor conocido como Paracelso (1491-1541) fue un auténtico revolucionario del pensamiento científico. Nació cerca de Zürich y se graduó en Ferrara, donde fue estudiante de Leoniceno. Se dedicó a la crítica de los clásicos y de sus ciegos seguidores, lo cual lo llevó a quemar públicamente los textos de Galeno y Avicena cuando asumió como profesor de medicina en Basilea y a renegar del latín como idioma de la ciencia para adoptar la escritura y la enseñanza en alemán. Firme partidario de los remedios químicos, por lo cual se le consideró el padre de la farmacología, basada en nociones metafísicas de la fisiología humana ${ }^{21}$.

La doctrina médica de Paracelso era compleja y sostenía una serie de principios que relacionaban lo general con lo particular, revisando ampliamente la patología de los diferentes órganos y sistemas, siempre sosteniendo una fuerte influencia metafísica en su concepción de la enfermedad y la salud. Vale la pena destacar aquí el concepto de localismo y especificidad que Paracelso asignaba a la formación del tartarus a partir del proceso de la digestión ${ }^{22}$

Probablemente la figura más importante de la cirugía (y por lo tanto de la odontología) del Renacimiento fue un hombre de origen campesino, que no tuvo acceso a la educación formal y a la medicina académica. Su nombre es Ambroise Paré (1517-159023). En 1561, publicó un tratado magnífico llamado Cirugía Universal. Luego, en 1563, sus famosos Diez Libros de Cirugía donde incorporaba nuevos procedimientos quirúrgicos y nuevos instrumentos. Finalmente, sus Obras Completas, en $1575^{24}$.

Ambroise Paré promovió la práctica quirúrgica general y estomatológica desde una simple actividad artesanal al nivel de una disciplina médica basada en la anatomía, la fisiología y la patología.

De padres alemanes, Andrea Vesalio (1514-1564) nació en Bruselas y estudió en la Universidad de Padua, ciudad que al estar fuera de la influencia papal, permitía las disecciones en cadáveres. De humani corporis fabrica, publicado en 1543 en Basilea con ilustraciones de un discípulo de Tiziano, contiene capítulos destinados a las

consejos prácticos revelan un acercamiento meditado, ético, razonable y prudente. (Ibid).

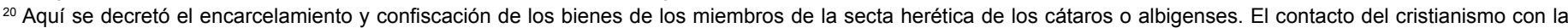

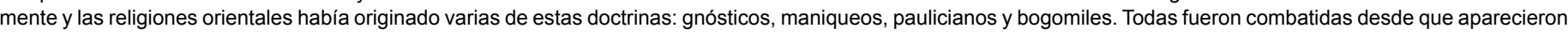
simultáneamente cerca de Toulouse y en el sínodo de Orleáns el año 1022. ( $\mathrm{N}$. del A.).

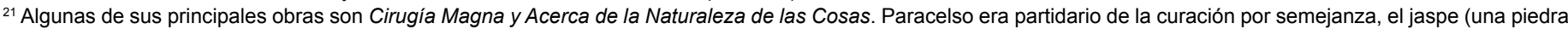

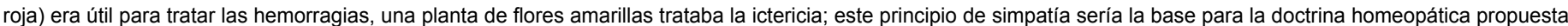
por Samuel Hahnemann (1755-1843) que sustenta que lo similar cura lo similar, "similia similibus curentur". (Lyons A. Op. Cit).

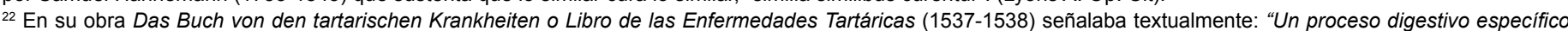

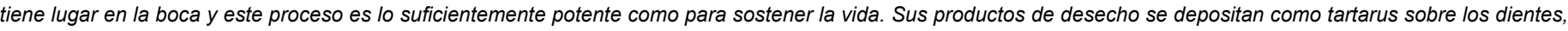

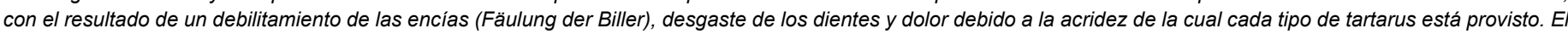
dolor de muelas es por lo tanto comparable al dolor causado por los cálculos en otras localizaciones". (Pagel W. Op. Cit).

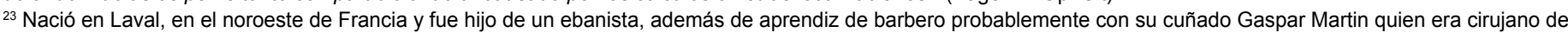

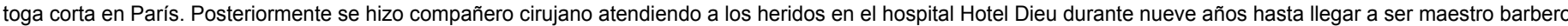

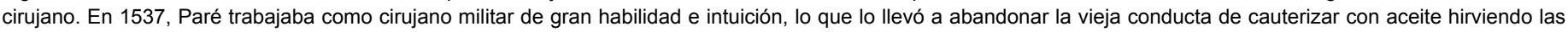

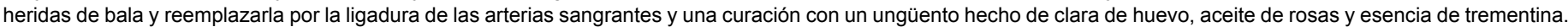
En 1554, Enrique II lo nombró maestro cirujano, a pesar de su formación no universitaria. (Ring m. Op. Cit).

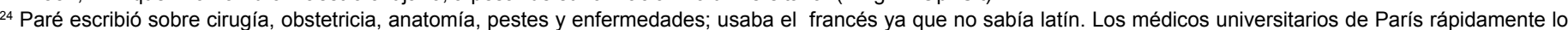

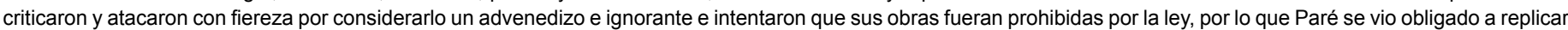

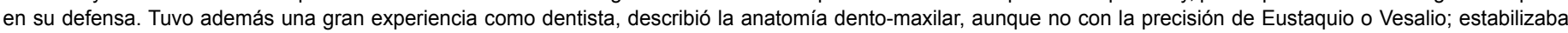

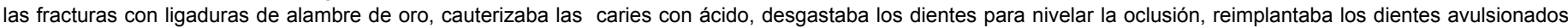

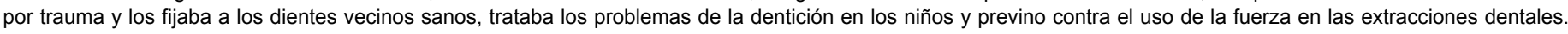

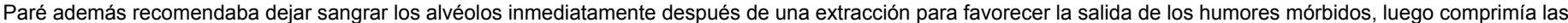

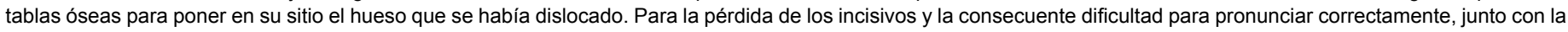

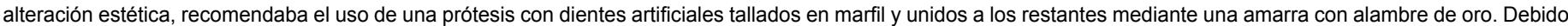

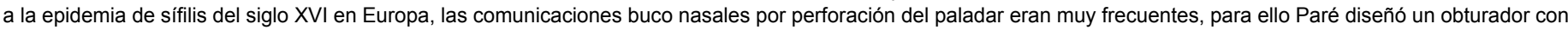
una fina lámina de metal que se adaptaba al paladar y una esponja que penetraba en la fosa nasal, absorbía las secreciones y fijaba dicho obturador. (Ibid). 
estructuras orales y dentales, reconociendo que los órganos dentarios son diferentes del hueso. El primer alumno de Vesalio fue Mateo Realdo Colombo (1516?-1559) quien publicó De re anatomica el año de su muerte; en ella describió en un feto los esbozos embrionarios de los dientes primarios. Más tarde, Gabriel Falopio (1523-1562) analizó con detalles el folículo dental, demostrando que las piezas primarias se formaban independientes de las definitivas. Además, demostró por observación directa que el maxilar superior no es un solo hueso y describió la sutura intermaxilar ${ }^{25}$. Falopio describió también los nervios trigémino, glosofaríngeo, la cuerda del tímpano y los conductos semicirculares, constituyéndose en un heredero de Erasístrato (de Alejandría) y del mismo Galeno. Sin embargo, el primer anatomista dedicado a la estomatología fue Bartolomeo Eustaquio (¿?-1574), también discípulo de Vesalio, quien hizo contribuciones como la trompa del rinofarinx que lleva su nombre, la musculatura profunda del cuello y descripciones de la vía aero-digestiva superior. Su obra Libellus de dentibus u Opúsculo sobre los dientes, publicado en 1563, fue el primer libro dedicado exclusivamente a la anatomía e histología de los dientes ${ }^{26}$.

Jerónimo de Brunschwig (ca.1450-1533) escribió un tratado sobre cirugía militar denominado Libro de cirugía de las heridas ${ }^{27}$. Anónimo de 1530 en Leipzig Opúsculo de medicina para todo tipo de desarreglos y enfermedades de los dientes ${ }^{28}$. En 1547 el sacerdote y médico Andrew Boorde, canciller de la Iglesia Anglicana, publicó Breviarie of Helthe ${ }^{29}$. Francisco Martínez de Castrillo, natural de la villa de Onielo en Palencia, España, publicó en 1557 su Coloquio breve y compendioso sobre la materia de la dentadura y maravillosa obra de la boca ${ }^{30}$.

El médico y científico español Francisco Hernández fue enviado por Felipe II a estudiar las ciencias naturales del nuevo continente y, conociendo las habilidades y competencias de los médicos aztecas, les manifestó siempre un gran respeto. De igual forma, el adelantado Diego de Almagro y el mismo Pedro de Valdivia trajeron médicos indígenas incaicos en sus expediciones a Chile. La terapéutica precolombina estaba basada en la herbolaria y la cirugía como métodos prácticos y en una integración entre el humano y el universo en una aproximación epistemológica tanto como cosmológica. Moctezuma en
México, Atahualpa en Perú y con toda seguridad también los mayas de Yucatán, desarrollaron viveros enormes dedicados al cultivo de las plantas medicinales.

El arte quirúrgico americano precolombino era digno de destacarse por su habilidad para reparar heridas, reducir fracturas, cohibir hemorragias, prevenir las infecciones y realizar las trepanaciones rituales del cráneo. En estas habilidades y destrezas, los nativos del nuevo continente no eran inferiores a los médicos de las civilizaciones arcaicas del resto del mundo. Estas competencias también eran aplicables en el campo de la odontología, la cual no era un ámbito diferenciado de resto de la práctica médica; las extracciones, fracturas ,abscesos y otra patología quirúrgica como labio leporino y otras malformaciones faciales, fueron parte del quehacer de los médicos originarios americanos. Los mayas usaban la escarificación, el tatuaje y el desgaste dental como una práctica ritual y mágica ${ }^{31}$.

En 1931 Wilson Popenoe encontró un cráneo en Honduras, cuya mandíbula presentaba tres trozos de concha marina tallados e implantados en la posición de los incisivos. Estudios imagenológicos posteriores mostraron que éstos se encontraban rodeados por hueso sano y formado de la misma manera como lo hace el hueso alrededor de los implantes de titanio, sin interfase fibrosa entre hueso e implante.

Fray Bernardino de Sahún escribió entre 1547 y 1577, Historia General de las Cosas de Nueva España ${ }^{32}$. Sebastián Garcilaso de la Vega, apodado "el Inca", nació en el Cuzco, virreinato del Perú, el 12 de abril de 1539 fue el gran cronista mestizo peruano y su obra más conocida es Comentarios Reales de los Incas ${ }^{33}$

Los conquistadores trajeron las ideas del Renacimiento y de la Contrarreforma española encabezada por la corona y la Iglesia. Por el lado americano, un conjunto de culturas originarias que se encontraban fuertemente arraigadas a la tierra de origen a través de costumbres, ritos, usos y conocimientos. Los pocos hombres de ciencia que llegaron durante el siglo XVI a América se sintieron inundados al mismo tiempo por un respeto hacia el patrimonio cultural aborigen y por un rechazo hacia costumbres y creencias consideradas como bárbaras y no cristianas. Sin embargo, de la unión de estos dos mundos surge la matriz de los pueblos

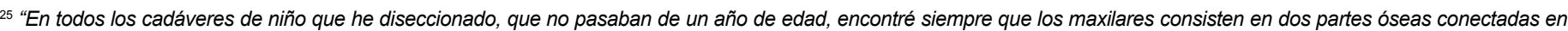

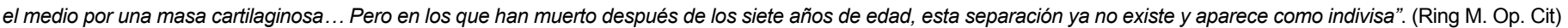

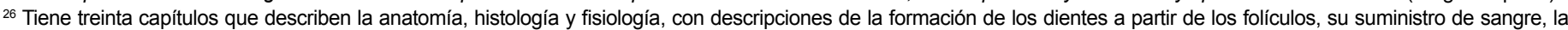
morfología de las cámaras pulpares y su forma de crecimiento. (lbid)

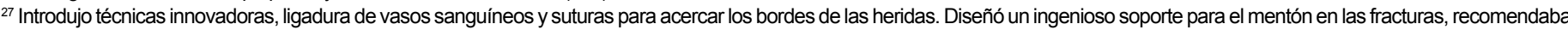
alinear y amarrar dientes y hueso con alambre en las fracturas de los maxilares con múltiples fragmentos y trataba las luxaciones de la mandíbula con vendajes inmovilizadores. (Ibid)

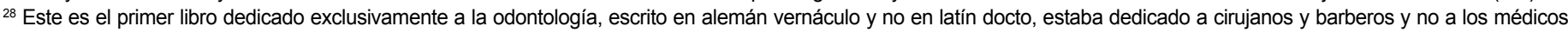

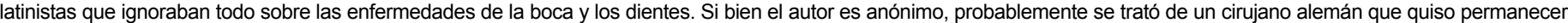
oculto para no sufrir el desprecio de una sociedad para la que el profesional de la cirugía y de la odonto-estomatología era de baja categoría. (Ibid)

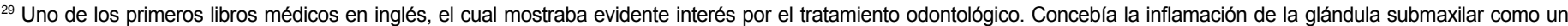

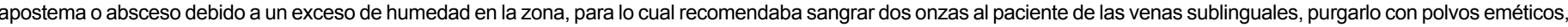

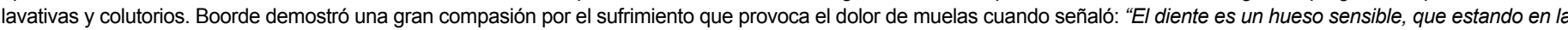
cabeza de un hombre vivo tiene sentimiento, más que cualquier otro hueso del cuerpo humano; y por lo tanto el dolor de muelas es un dolor extremo". (Ring M. Op. Cit)

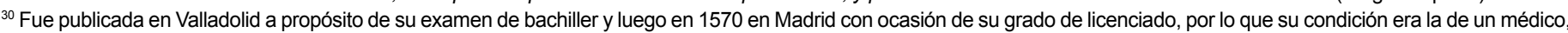

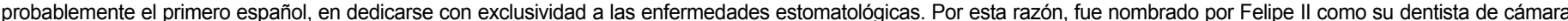

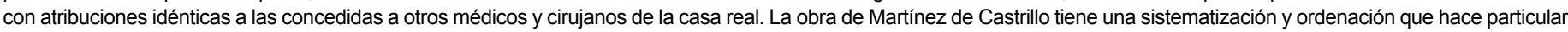

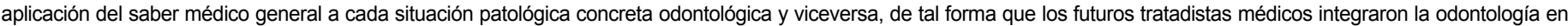
sus textos. Febres cordero F. Op. Cit)

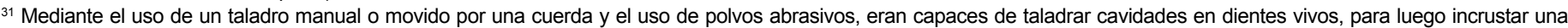

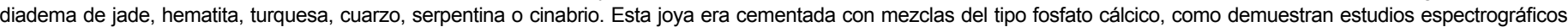

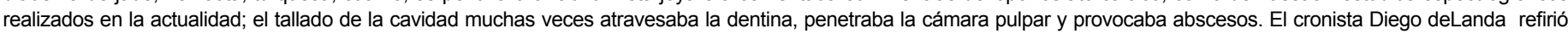

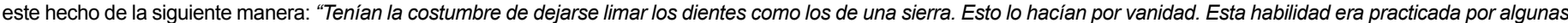
ancianas que usaban para ello agua y piedras". (Ring M. Op. Cit)

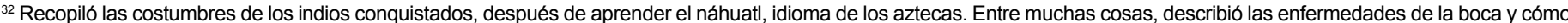

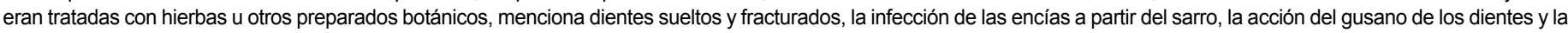

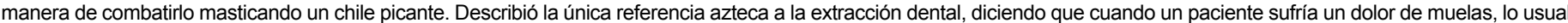

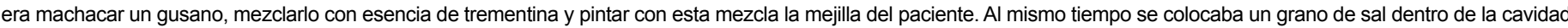

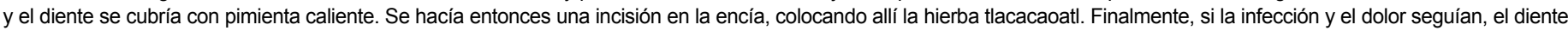
era extraído. Refiere Sahún que los aztecas también suturaban heridas de los labios y las mejillas. (Ibid)

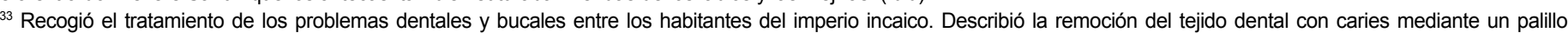

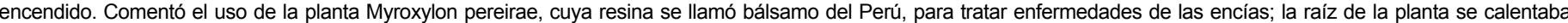

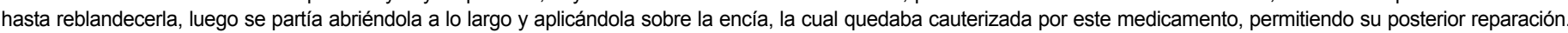

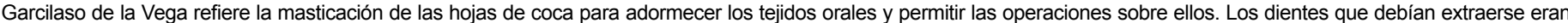

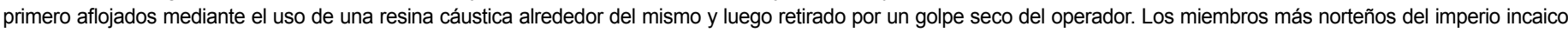

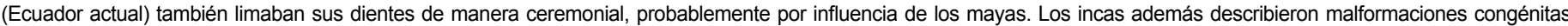

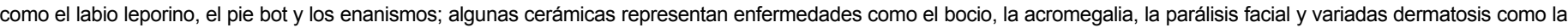
verruga peruana. (lbid) 
iberoamericanos, mestizos por definición y herederos tanto del saber positivo europeo como del conocimiento intuitivo de los antepasados originarios.

En España, los Reyes Católicos dictaron la ley del 30 de marzo de 1477 que creó el tribunal del protomedicato, institución que regulaba a los profesionales de la salud en nombre del reino de Castilla, normativa que fue sucesivamente modificada y perfeccionada en 1491, 1498 y después por Carlos V en 1523 y Felipe II en 1552, quienes iniciaron la conquista del continente americano. Para ello enviaron, junto con los soldados y sacerdotes a sus médicos y cirujanos.

La historiografía no ofrece referencias respecto de la práctica odontológica en el Chile del siglo XVI, pero podemos suponer que los diferentes profesionales médicos atendían los dolores, infecciones, trauma y otras enfermedades orales, apoyados en la farmacopea rudimentaria de las boticas, en la experiencia práctica de algunos cirujanos certificados, en algunos barberos y sangradores que hacen extracciones dentales y drenan abscesos y, muy probablemente, en la tradición médica popular indígena de origen quechua, aymara, diaguita $\mathrm{y}$, posteriormente, mapuche.

El proceso de asentamiento de la medicina hispánica, que incluyó medicina y cirugía y dentro de esta última, la estomatología, se lleva a cabo en forma heroica y sacrificada durante cuarenta años, hasta fines del siglo XVI.

Grandes exponentes españoles de esa época fueron Francisco de Arceo (1493-1571) y Dionisio Daza Chacón (1513-1596) quienes reformaron la cirugía ${ }^{34}$. En anatomía, Juan Valverde (15251588) y su obra Historia de la composición del cuerpo humano ${ }^{35}$.

Los médicos eran formados en las universidades españolas bajo las normas de la escuela hipocrática y galénica clásica, donde recibían el grado de bachiller y después de comparecer ante el tribunal del protomedicato, obtenían el título para ejercer. Estos médicos bachilleres eran pocos y atendían a las casas reales, a los nobles y a los ricos burgueses 0 , a veces, se encargaban de dirigir los hospitales. La gran masa del pueblo español no recibía atención de los médicos latinistas universitarios. Por otro lado, los cirujanos latinistas y romancistas, eran asignados al ejército y emigraban a los territorios de la conquista acompañados por barberos, sangradores y boticarios.

En la ordenanza del 7 de octubre de 1541, Carlos V decretó la obligatoriedad de fundar hospitales en las nuevas ciudades y, luego, en 1563, Felipe II fijó los requisitos y conocimientos de los farmacéuticos para poseer y administrar boticas en las ciudades españolas, cuya supervisión quedó bajo la tutela de los cabildos. Durante el reinado de Felipe II entre 1556 y 1598, el virreinato del Perú mantenía una guerra en dos frentes: Arauco y contra los corsarios protestantes. Chile era, por esta razón, un hito extremo del imperio español y, mientras en México se escribían libros de medicina, en Chile no había hospitales ni personal médico alguno.

El primer hospital en Chile se fundó en Santiago en 1552 en honor a la Virgen del Socorro. El segundo se fundó en La Serena el 14 de agosto de 1559. En 1553 había en Santiago dos médicos y una botica controlada por el cabildo ${ }^{36}$. Los españoles derrotaron a Lautaro en Peteroa en abril de 1557, fundaron Cañete y Osorno en 1558, repoblaron Arauco, Concepción y Angol en 1559 y edificaron iglesias y hospitales como el de San Cosme y San Damián de Osorno (1558), el de Nuestra Señora de la Misericordia de Concepción (1559), el de Nuestra Señora de la Asunción de La Serena (1559), el de San Julián de La Imperial (1557) y antes de terminar el gobierno de Hurtado, el hospital del Socorro en Santiago. En Villarrica funcionó un hospital hasta la reconquista mapuche de $1602^{37}$.

\section{ODONTOLOGÍA EUROPEA DEL SIGLO XVII AL HOSPITAL CLÍNICO UNIVERSITARIO}

En el siglo XVII se produce el cambio de orientación más importante en la historia de la ciencia: en vez de preguntarse por qué suceden los fenómenos, los científicos comienzan a preguntarse cómo suceden, es decir, crece la importancia de la experimentación frente al puro razonamiento especulativo.

La práctica médica era difícil de controlar, a pesar de los esfuerzos del colegio profesional que intentaba regular el ejercicio de médicos, cirujanos, barberos, farmacéuticos y otros como sangradores y sacamuelas. En 1617 los farmacéuticos de Londres formaron su propia asociación gremial, separada de los comerciantes. En un principio funcionaban en dependencia de la receta del médico, pero con los años fueron adquiriendo mayor autonomía a tal punto que a fines del siglo XVII se consideraban al mismo nivel que los médicos generales.

La odontología la practicaba indistintamente quien se sintiera con la capacidad para hacerlo: había ilustres médicos que atendían las dolencias dentales de sus pacientes poderosos, cirujanos que reparaban todo tipo de dolencias orales en los heridos de guerra y también civiles, algunos farmacéuticos practicaban sangrías y extracciones dentales y, por último, la escasez de profesionales generó un grupo importante de prácticos ambulantes que aprendieron el oficio en forma directa y sin ningún estudio. En 1699, Luis XIV promulgó un edicto que establecía el status profesional de los dentistas de Francia, por lo que debían seguir cursos por dos años en el Colegio de Cirujanos, formando así un nuevo grupo dentro del gremio, el de los cirujanos-dentistas.

Los cirujanos fueron los que mayores avances produjeron durante el siglo XVII, a pesar de que fueron muy despreciados por los médicos. Después de los trabajos de Paré y de los avances en la anatomía por medio de la disección, la cirugía tuvo un desarrollo importante y, bajo su alero, también lo tuvo la odontología.

Wilhelm Fabry von Hilden (1560-1624 ó 1634) fue un destacado cirujano alemán quien escribió una obra llamada Observationes et curaciones $^{38}$. Richard Wiseman (1622-1676) fue el cirujano inglés que escribió la obra Several Chirurgical Treatises ${ }^{39}$ (1672). El alemán Johann Schultheiss publicó en 1655 su obra Armamentarium Chirurgicum ${ }^{40}$.

En Francia, los médicos despreciaban a los cirujanos y los cirujanos despreciaban a los barberos; pero en 1655 se vieron obligados a formar una asociación de cirujanos y barberos; los primeros se beneficiaron de la experiencia de los segundos, éstos del prestigio de los cirujanos y ambos quedaron bajo la supervisión del cirujano real quien tenía status médico.

En México y Lima se construían hospitales, se fundaban escuelas de medicina, se exportaban los medicamentos del Nuevo Mundo y se editaban libros médicos en español, todo lo cual alcanzó su máximo esplendor durante el reinado de Carlos III en el siglo XVIII o de la llustración. Recordemos que fueron prioritariamente los profesionales del arte quirúrgico los que atendían las necesidades estomatológicas de la comunidad, ya que los recursos terapéuticos de los médicos eran limitados a unas cuantas plantas para las infecciones y dolores de muelas y, por otra parte, la práctica de la cirugía era considerada por ellos como una actividad indigna.

Imaginemos algunas tareas para un cirujano en la fortaleza de Concepción en medio del triunfo de Lientur en Las Cangrejeras en 1629. El gobernador se refugió en Concepción y sostuvo con dificultad Valdivia, donde funcionaba un hospital. Los cirujanos y médicos militares, laicos los menos, religiosos hospitalarios la mayoría, atendían

\footnotetext{
${ }^{34}$ De la misma manera como lo hiciera Ambroise Paré en Francia. (N. del A.)

${ }^{35}$ Fue un continuador del belga Andreas Vesalio y su obra fue el primer texto en castellano de anatomía moderna. (Lyons A. Op. Cit)

${ }^{36}$ Esta institución tuvo un rol importante en la prohibición a los prácticos no certificados para ejercer medicina y, sobre todo, cirugía. (Cruz Coke R. Op. Cit).

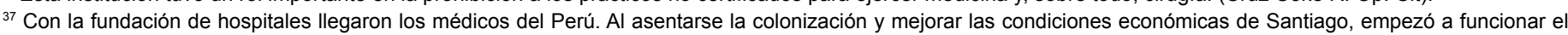

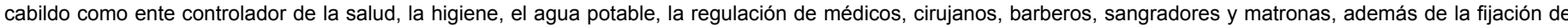

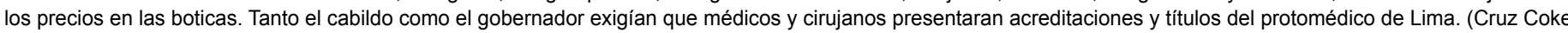
R. Op. Cit).

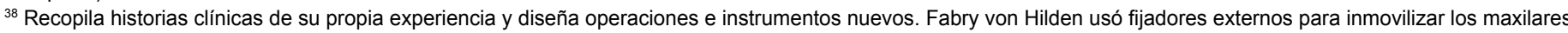

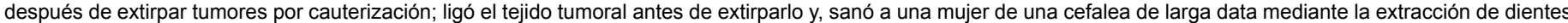
maxilares infectados. (Ring M. Op. Cit)

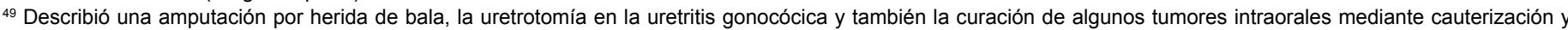
ligadura. (Ibid)

${ }^{40}$ Describió la curación de un quiste del maxilar después de ser drenado a la cavidad oral y posteriormente extirpado. (Ibid)
} 
con remedios limitados. Aunque se conocian somníferos, opioides y calmantes, todavía no se desarrollaba la anestesia, ni local ni general. Entre 1617 y 1664 el hospital San Juan de Dios atendió 26.230 pacientes. No sabemos cuántos se debieron a patología quirúrgica, pero podemos suponer los esfuerzos de los cirujanos militares por mantener una tropa operativa en medio de la guerra. Las descripciones del estado del arte estomatológico en el siglo XVII europeo permiten suponer con cierta razón que no serían raros los pacientes de infección y fracturas ${ }^{41}$. Llegando el herido, había que actuar con rapidez: lavar y curar primariamente las heridas, con un paciente sedado por vía oral si el tiempo lo permitía, reducir e inmovilizar las fracturas y luego controlar, procurando la solución de las complicaciones, infecciosas y hemorrágicas principalmente.

Las tareas odontológicas eran ejercidas indistintamente por médicos, cirujanos y boticarios autorizados por los cabildos. Los más humildes eran atendidos en sus problemas dentales por barberos y sangradores.

Francia fundó en 1713 el Real Colegio de Cirujanos y prohibió a los barberos, 30 años después, la práctica quirúrgica. Inglaterra separó formalmente en 1745 las corporaciones de barberos y cirujanos, pero el Royal College of Surgeons no recibió hasta 1799 su status actual. Los descubrimientos científicos de los siglos precedentes introdujeron algunos cambios profundos en el ejercicio de la odontología. Después de siglos de haber sido practicado por médicos y cirujanos, principalmente $y$, por boticarios, sangradores y barberos en un segundo plano, el arte dental pasó a constituirse en una disciplina científica independiente. La cirugía europea del siglo XVIII llevaba una importante ventaja sobre el desarrollo de la medicina, la cual estaba muy retrasada. En 1684 el estado alemán de Brandemburgo, Prusia, dictaminó que los médicos, cirujanos y boticarios que deseaban ejercer el arte dental, debían examinarse previamente ante el Collegium Medicum de Berlín, quedando prohibida la práctica en manos de charlatanes y sacamuelas no certificados. En 1699 el parlamento francés aprobó una ley que obligaba a los dentistas (experts pour les dents), oculistas y componedores de huesos a ser examinados por un comité de cirujanos para ejercer en París y sus alrededores.

Pierre Fauchard ${ }^{42}$ (1678-1761) se formó como cirujano militar y se instaló en París hasta su muerte. A los 15 años se embarcó en la flota francesa, donde actuó como ayudante del cirujano mayor Alexandre Poteleret, quien estaba interesado hace años en las enfermedades de los dientes, especialmente en las lesiones orales en el escorbuto. Fauchard ejerció como cirujano en el hospital universitario de Angers donde adquirió fama como operador oral y como protesista. En 1699, Luis XIV promulgó un edicto que establecía el status profesional de los dentistas de Francia, por lo que debían seguir cursos por dos años en el Colegio de Cirujanos, formando así un nuevo grupo dentro del gremio, el de los cirujanos-dentistas. Fauchard no estuvo de acuerdo con el funcionamiento de la certificación de los cirujanos dentistas y solicitó su incorporación al comité creado por el edicto de 1699 , lo cual no fue aceptado. Desde un punto de vista gremial, Fauchard se separó de los cirujanos, pero también se diferenció de flebótomos y sacamuleas. Creó una profesión cuyos cultores se denominan en Francia cirujanos dentistas, los cuales fueron el modelo para los profesionales de Estados Unidos, quienes a su vez, serán los gestores de los mayores avances para el gremio en el siglo XIX.

John Hunter es considerado el padre de la cirugía experimental y su aporte a la estomatología se concentró en la espléndida obra publicada en 1771 y traducida al alemán, holandés, italiano y latín: "The Natural History of the Human Teeth: Explaining their Structure, Use, Formation, Growth and Diseases". El aporte de John Hunter a la estomatología fue científico más que práctico, ya que ejerció muy poco como dentista.

Nicolas Dubois de Chémant fue el cirujano dentista que logró producir buenos dientes de porcelana y restauraciones protésicas bien toleradas. En 1789, presentó su trabajo a la Academie des Sciences y, ésta, junto con la facultad de medicina de la Universidad de París, recibieron el invento con interés. Ese año, Luis XVI les autorizó una patente real. Dubois de Chémant huyó en 1792 de los excesos revolucionarios franceses rumbo a Inglaterra, la que le concedió un permiso para producir dentaduras de pasta mineral por catorce años y en 1797 publicó su libro Disertación sobre dientes artificiales ${ }^{43}$

El contexto médico chileno a fines del siglo XVIII muestra gran cantidad de médicos y cirujanos, laicos y religiosos, civiles y militares, españoles, criollos y extranjeros. Numerosos hospitales abiertos a la comunidad, gratuitos, obras de beneficencia pública, bien dotados de acuerdo a los tiempos. Varias boticas sucedieron a la de los jesuitas, habitualmente adosadas a los hospitales, bien provistas de una farmacopea europea y americana. En la Europa de la lluminación, Fauchard y sus seguidores, después de soportar los duros tiempos post revolucionarios, promovieron la distinción de la nueva profesión de cirujano dentista, lo cual realizaron con bastante éxito. Afianzaron la autonomía y jerarquía científica de sus cultores, influyeron sobre otras sociedades y consolidaron una posición académica universitaria y social. En la España de los monarcas ilustrados, se hizo más sólida la categoría científica de la estomatología como especialidad médica, la cual se venía cimentando en España desde 1557 con Francisco Martínez de Castrillo. No se produjo distinción alguna entre los médicos y cirujanos que practicaban la terapéutica odontoestomatológica. La atención de los pacientes con patología oral la realizaban indistintamente médicos, cirujanos, boticarios y barberos, según la complejidad del caso y según la condición social y económica del paciente ${ }^{44}$

Durante el siglo XVIII no se podía estudiar medicina y cirugía a la vez, básicamente porque los médicos consideraban la cirugía una profesión indigna. Mientras en Francia hizo su estreno la odontología como especialidad quirúrgica, emanando de un gremio de cirujanos con status médico desde comienzos del siglo XVII, en España se consideraba la atención dental una responsabilidad general del cirujano. En tanto, no hay registro de dentistas en Chile durante aquel tiempo.

Con la llegada del siglo XIX las universidades acrecentaron su rol como propulsoras del desarrollo científico y, más aún, de la tecnología al servicio de la sociedad. Pronto las aulas académicas fueron sobrepasadas por instituciones científicas asimiladas a la industria y a sus laboratorios ${ }^{45}$. La ciencia se transformó en una poderosa fuerza, salvadora y redentora, tanto del capitalismo como del proletariado. El científico era un "sabio-sacerdote" destinado a librar

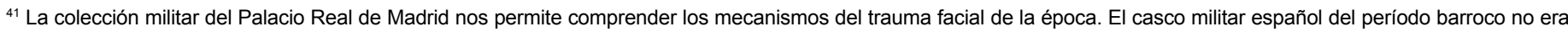
muy eficiente en la protección facial, por lo que las heridas de guerra, con las armas del momento, no deben haber sido infrecuentes o de poca complejidad. ( $\mathrm{N}$. del $\mathrm{A}$.)

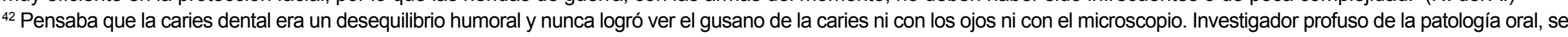

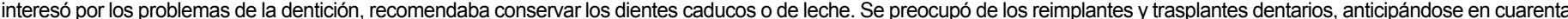

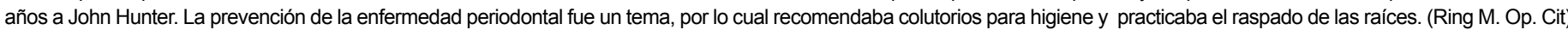

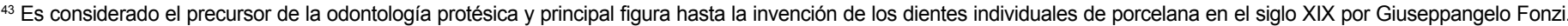
(Ring M. Op. Cit)

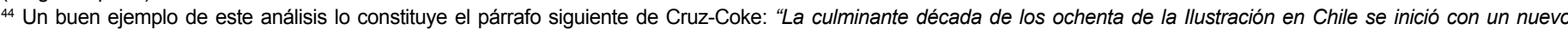

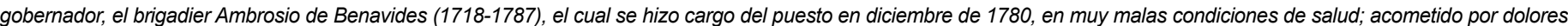

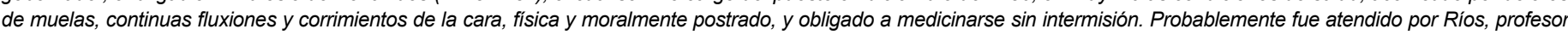

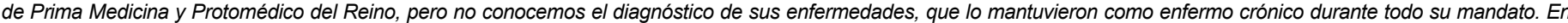

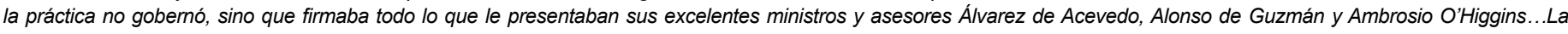

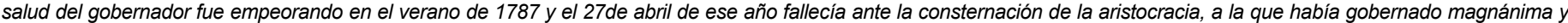

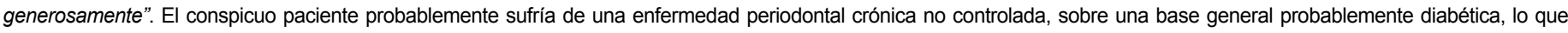

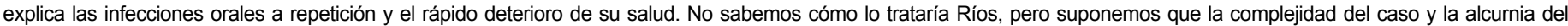
paciente, lo obligaron a hacer uso de toda su techne iatriké y probablemente a solicitar el concurso de algún cirujano del reino. (Cruz Coke R. Op. Cit)

${ }^{45}$ Por ejemplo la Georg Speyer Haus für Chemotherapie de Francfort, la Kaiser Wilhelm Gesselschaft de Berlín y la Rockefeller Foundation de Nueva York. (Lyons A. Op. Cit)
} 
a la humanidad del hambre y la enfermedad, trabajando en y para la libertad. Sin embargo, el análisis dialéctico capital-trabajo (burguesíaproletariado) mostró que la ciencia, por un lado, es motor de progreso y libertad y, por otro, es instrumento de dominación, tanto de clase como de unos estados sobre otros ${ }^{46}$.

París se transformó en el centro de la medicina europea después de la revolución francesa. Se sustituyó la especulación teórica por la observación directa del enfermo. El hospital se convirtió en el núcleo de la actividad médica. La salud pública pasó a ser responsabilidad del estado y la medicina llegó ahora a todas las clases sociales.

Los cirujanos se unificaron finalmente con los médicos, la enseñanza de las universidades cubrió ambas disciplinas por igual y comenzó a desarrollarse el fenómeno de la especialización médica. En aquel entonces, la práctica estomatológica estaba en manos de los cirujanos generales que practicaban incipientemente con avanzadas técnicas correctoras y nuevos abordajes quirúrgicos.

Una tecnología cerámica derivada de los químicos y farmacéuticos franceses hacía posible un arte protésico de mejor nivel cada vez, pero los mayores aportes en materia de tecnología dental tendrían que esperar hasta fines del siglo y comienzos del próximo.

La mayoría de los prácticos dentales no tenían certificación y eso había influido en el esfuerzo colegiado de Fauchard ${ }^{47}$. Francia unificó pronto los títulos de médico y cirujano manteniendo el de cirujano-dentista. La educación para el desarrollo de la ciencia al servicio del pueblo sería tal vez la consigna post revolucionaria en 1830 o 1848 y, con seguridad creciente, burgueses y proletarios piden atención dental eficiente hasta el día de hoy. Los "dental practitioners" eran en el Reino Unido cirujanos como John Hunter o prácticos no certificados. En los otros países europeos eran médicos, cirujanos, farmacéuticos o prácticos no certificados la mayoría. Los cirujanos dentistas franceses fueron los más cotizados del comienzo del siglo y, movidos por el libre mercado del ejercicio y de la enseñanza, se desarrollaron con fuerza también en los estados de la unión, post 1776 y en lo que serán las zonas de influencia de los Estados Unidos.

A contar de este momento la odontología se hace fuerte en una práctica pública a nivel de los hospitales y en una enseñanza de nivel universitario ${ }^{48}$. Los hospitales universitarios, modelo de la moderna enseñanza médica en el mundo, contaron en forma permanente con profesionales del arte dental capaces de transmitirlo como una techné a los estudiantes, junto al paciente y para el servicio del derecho de la comunidad al bien que es la salud.

En Chile, durante el siglo XVIII, no hay registro de práctica dental por parte de cirujanos dentistas, por lo que suponemos con cierto grado de certeza que la odontología fue ejercida, al igual que en siglos anteriores, por médicos, cirujanos, boticarios y sangradores. Durante el 1700 se produjo un gran auge de la odontología francesa, empujada por Fauchard y sus discípulos, los cuales propagaron su influencia hacia los Estados Unidos e Iberoamérica. En Chile, durante el siglo XVIII, no conocemos evidencias de atención dental por cirujanos dentistas y, al parecer no la hubo hasta 1828 cuando la sociedad médica que actuaba en representación del estado de Chile, autorizó a los franceses Simón Retou y Mauricio Cazaneuve para ejercer la odontología en Valparaíso. Luego, el tribunal del protomedicato, dirigido por Blest, en 1834 otorgó su beneplácito para que José Coupelon y su socio Eugenio Del Cambre trabajaran como dentistas en Valparaíso y Santiago, a juzgar por el aviso que aparece en El Mercurio, el cual dice: "Se sacan las muelas y los dientes gratis a los pobres, todos los días desde la 1 hasta las 3 P. M." 49 .

Al parecer el primer dentista de origen propiamente chileno fue José León Estrada, quien fue discípulo de Del Cambre por 16 meses y obtuvo en 1839 la autorización para trabajar por parte del tribunal del protomedicato del estado chileno. Domingo Lagunas es nombrado por el entonces presidente del tribunal, Nataniel Cox, ministro de fe permanente para examinar a los postulantes a dentista. Posteriormente, en 1841, los franceses Logerost y Calmet, aprueban ante el tribunal los exámenes que los facultan para ejercer. Luego, en 1849, Gelinet se hace famoso por la calidad de sus tratamientos. En 1852 Louis Berthon obtiene licencia para ejercer y en 1854 publica su Ensayo sobre Higiene Dentaria y obtiene el título de dentista en $1868^{50}$.

La nueva escuela de medicina de la estatal y gratuita Universidad de Chile tuvo su período de esplendor entre la inauguración por Balmaceda en 1889 y el comienzo de la dictadura de Ibáñez en 1927, cuando se destruyó la autonomía universitaria. Durante este lapso se consolidaron los progresos científicos del positivismo, nacieron las ciencias biomédicas básicas y clínicas y se establecieron todos los programas para la especialización y formación de post grado. Se fundaron las escuelas de odontología y farmacia dentro de la facultad de medicina y se apoyó la creación de una nueva escuela de medicina en Concepción.

El edificio de la calle Independencia era un palacio con una imponente fachada de seis columnas griegas en medio de un jardín rodeado de palmeras. La construcción tenía la forma de un rectángulo de dos pisos, con dos patios, anterior y posterior; en el primero estaban las salas de anatomía, cirugía, el museo, oficinas administrativas y salas de profesores; en el segundo, los laboratorios de histología, patología, zoología, botánica y dentística. Además había un anfiteatro para 300 personas. En años siguientes, se instalaron en el patio posterior los laboratorios de física, química y farmacia, cuyas clases se hacían en un comienzo en el edificio de la casa central en la Alameda. Hacia 1910 se instaló la biblioteca en el patio anterior. El decanato de medicina estaba en el segundo piso de la casa central, justo sobre la rectoría. Al costado sur de la escuela, el hospital San Vicente de Paul con sus 300 camas de hombres y 120 de mujeres, con sus clínicas médicas y quirúrgicas dispuestas para la docencia. En 1911 se creó la posta $N^{\circ} 2$ de la Asistencia Pública, en la avenida Independencia. Entre 1925 y 1927 se construyó el edificio de la maternidad, sobre la entonces calle Panteón, hoy día Zañartu. Finalmente, en 1920 se inauguró el pensionado del hospital, adosado a la posta por el sur.

En 1892 la nueva escuela reabrió sus aulas, contando en sus autoridades a los más importantes médicos de la época y a J. J. Aguirre como rector. Vino el período de auge de la enseñanza médica y de las becas para las nuevas especialidades: Carlos Ibar viajó a estudiar pediatría y dermatología; Aureliano Oyarzún, patología; Luis Albarracín, Daniel Rioseco y Ernestina Pérez, otras disciplinas. Entre 1895 y 1901 ejerció como decano el profesor Ventura Carvallo Elizalde (1854-1917), quien contó con el apoyo de dos rectores médicos: Diego San Cristóbal (1897-1900) y Manuel Barros Borgoño (19001903), gracias a lo cual se produjo una fuerte transferencia científica desde Europa.

Varios fueron los intentos por lograr una enseñanza universitaria de la odontología en Chile. Desde la fundación de la universidad estatal en 1842, la facultad de medicina se encargó de regular el ejercicio de las profesiones médicas a través de sus primeros decanos Lorenzo Sazié y José Joaquín Aguirre, quienes eran por ley protomédicos del estado chileno. Para ello, se encomendó al medico Pablo Zorrilla en 1865 para que organizara un curso destinado a formar flebótomos. Dado que muchas prestaciones dentales eran ejercidas por sangradores desde la Edad Media, hoy algunos consideran que éste sería un intento fundacional de la odontología universitaria chilena. Nuevamente, en 1867, el médico Miguel Semir recibió un encargo similar, pero no hay claridad respecto a que realmente se logró enseñar odontología como se practicaba en ese momento en Francia y en los Estados Unidos y, por lo tanto, esos cursos no constituyeron precedente ni aporte al desarrollo de la enseñanza de la estomatología en Chile.

El decano Vicente Padín del Valle, finalizó su período al frente de la facultad, proponiendo un plan de estudios de dentística, que al parecer no estaba relacionado de manera alguna con los

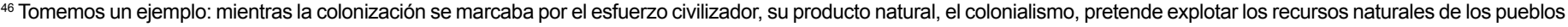
dominados para estimular la economía central. (Berlinguer G. Op. Cit)

${ }^{47}$ Los dentistas franceses se certificaban ante el colegio de cirujanos y los estadounidenses estudiaban libremente en "dental schools". (Ring M. Op. Cit)

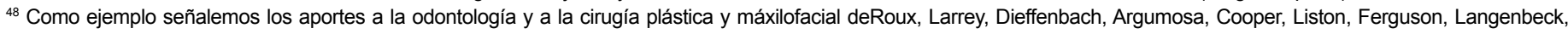
Reverdin, Ollier y Thiersch. (Lyons A. Op. Cit).

${ }^{49}$ Colin J. Op. Cit).

${ }^{50}$ Colin J. Op.cit
} 
cursos previos para flebótomos y que, aunque no logró concretarse de manera clara, constituyó el primer intento serio para enseñar odontología en la facultad de medicina. La carrera de odontología se estableció en forma muy rudimentaria en una sala del hospital San Vicente en 1889, bajo la conducción de los médicos Nemesio Ávila y Eulogio Cortínez.

El decano Ventura Carvallo Elizalde envió a su ayudante de la cátedra de cirugía, Germán Valenzuela Basterrica (1864-1922) en 1897, a especializarse en estomatología a París, de donde regresó definitivamente en 1904 con el título de cirujano dentista además de aquel de médico cirujano obtenido en Chile previamente. La visión del decano de la época fue la de establecer en el país una enseñanza moderna y de elevado nivel científico para la odontología y, fue con ese propósito que envió a Valenzuela Basterrica a graduarse en Francia. A su regreso en 1904, Germán Valenzuela fue director de la carrera de odontología de la facultad de medicina, aumentó el plan de estudios a tres años y exigió un bachillerato en humanidades para el ingreso, cosa que recién será realidad en 1911, con la creación de la nueva escuela dental. El plan de estudios era similar al francés, aumentó las exigencias para el ingreso de los interesados y promovió desde la dirección de la nueva escuela dental (1911) un concepto científico y médico de enseñanza y práctica odonto-estomatológica en Chile.

Antes de la creación de la Escuela Dental en 1911, la odontología estuvo subordinada a la medicina como un saber técnico - médico, sin reconocimiento científico y social. Recién en 1911, con la intervención del Dr. Germán Valenzuela Basterrica en el caso Beckert, esta visión de la odontología cambia, iniciándose un periodo de trascendencia jurídica y científica de la profesión del cirujano dentista chileno.

Antes del caso de la legación alemana, la dentística como se le denominaba despectivamente, era un saber técnico, asociado a veces a la flebotomía, donde incluso, no se pedía la enseñanza de humanidades completa, lo que denigraba este conocimiento científico dentro del marco de la Facultad de Medicina.

El Dr. Valenzuela logra con su intervención, la autonomía de la disciplina, la incorporación de la ciencia odontológica como parte del proyecto de estado benefactor, el reconocimiento social y la creación de una escuela moderna de esta ciencia que se proyectará como la más importante del siglo XX, hasta la actualidad.

Este modo de enseñar se mantuvo bajo el alero de la facultad de biología y ciencias médicas de la Universidad de Chile hasta la creación de la facultad de odontología en mayo de 1945. Esta separación en facultades diferentes tuvo razones que, en su momento, fueron consideradas como de peso suficiente para conseguir que la rectoría autorizara la escisión. La historia del desarrollo de la odontología en Chile durante el siglo XX mostrará un crecimiento en complejidad, prestigio y cobertura.

En Chile, la odontología se consolidó como disciplina médica a nivel hospitalario durante la época del parlamentarismo y de la medicina científica (1891-1927). En 1892 se estableció formalmente el primer consultorio externo de especialidades en el dispensario del hospital San Juan de Dios: medicina general, cirugía general, pediatría, ginecología, oftalmología, otorrinolaringología, venereología, urología y servicio dental.

En 1912, todos los profesores del área clínica eran médicos de sala del hospital y actuaban también en los dispensarios de especialidades: Alfredo Commentz en pediatría; Alejandro Mujica en oftalmología; Luis Puyó en dermatología; Luis Plaza en dentística; Hugo Lea Plaza en radiología; Víctor Wiren en otorrino; Alejandro Infante en fisiatría, entre otros. En 1922, la planta de jefes de servicio del hospital San Juan de Dios contaba entre otros a Germán Valenzuela Basterrica y Alberto Rahausen como jefe y ayudante de cirugía y a Juan Eduardo Rojas como jefe de odontología ${ }^{51}$.

En 1945, la escuela dental de la facultad de medicina de la Universidad de Chile, institución pionera en la educación superior de nuestro país, decide separarse y constituirse como facultad de odontología, al igual que hace también farmacia, que estuvo desde el origen dentro de medicina. Las razones de esta decisión parecen guardar relación con el acceso a un cierto nivel de autonomía para el desarrollo. Pero, lo cierto a juicio de muchos, es que significó en la práctica la adscripción a un modelo de enseñanza del tipo estadounidense, con todas las fortalezas y debilidades que esto conlleva. A saber: como debilidad una capacitación cuestionable, al menos, en materia médica y peligro de subordinación en el ejercicio profesional y, como fortaleza, una fuerte condición de vanguardia en la investigación y desarrollo del área específica odontológica.

Este modelo fue adoptado igualmente en Chile por las universidades de Concepción y de Valparaíso. Cuando la dictadura de Augusto Pinochet atomiza la universidad estatal y nacional, desmembrándola en varias sedes regionales autónomas, como Talca y Antofagasta, éstas siguen el mismo modelo. Posteriormente, en 1980, cuando se modifica la educación superior chilena, permitiendo la fundación de nuevas universidades públicas y privadas, el modelo de enseñanza sigue siendo idéntico, es decir, poniendo énfasis en lo particular de la profesión odontológica por encima de la formación médica general.

Para asegurar el libre tránsito de los diferentes profesionales por el espacio económico de la Unión Europea, los ministros de educación comunitarios firmaron la declaración de Bolonia de 1999, la cual intenta una convergencia y armonía de los sistemas de educación superior a fin de crear en 2010 un área europea de educación superior. Así, definen al cirujano-dentista como un profesional específico y distinto del médico-cirujano, con un perfil de competencias que luego serán determinadas por la asociación para la educación dental en su asamblea general de Cardiff $(2004)^{52}$ y revisada en Birmingham (2008) ${ }^{53}$. Para la adquisición y desarrollo de este perfil de competencias mínimas sugieren "un currículo que provea una exposición a materia médica relevante a la práctica odontológica, que incluya un rango de experiencias didácticas y clínicas específicas". Ha prevalecido entonces una educación universitaria para el cirujanodentista que privilegia el cuidado especial de la boca, los dientes y los maxilares, sin renunciar por ello a una capacitación suficiente en materia médica general ${ }^{54}$

\section{CONFLICTOS DE INTERÉS}

tipo.

El autor declara no presentar conflictos de interés de ningún

\section{REFERENCIAS BIBLIOGRÁFICAS}

1. Berlinguer G et al. Medicina y Sociedad. Libros de Confrontación. Editorial Fontanella. Barcelona. 1972.

2. Besio M. Sobre el acto médico. Curso Fundamentos Filosóficos de la Medicina. Pontificia Universidad Católica de Chile. Santiago, pág.6. 2008.

3. Colin J. Investigación histórica de la Facultad de Odontología. Impresos Universitaria S. A. Santiago. 1997.
4. Cowpe J. Profile and competentes for the European dentista. Update. Birmingham, 2008.

5. Cruz Coke R. Historia de la medicina chilena. Edit. Andrés Bello. Santiago. 1995.

6. Febres Cordero F. Orígenes de la Odontología. Sociedad Venezolana de Historia de la Medicina. Caracas. 1966.

\footnotetext{
${ }^{51}$ El código sanitario chileno, promulgado en 1918, confiere en su artículo 115 al cirujano dentista la responsabilidad de las prestaciones odonto-estomatológicas

${ }^{2}$ Plasschaert A. (2004). Perfil y competencias del odontólogo europeo. Asociación para la educación dental en Europa. Cardiff.

${ }^{53}$ Cowpe J. (2008). Profile and competences for the european dentist. Update. Birmingham.

${ }^{54}$ Cowpe J. Óp. Cit.
} 
7. García Palao A. Historia y Actualidad de la Cirugía Máxilo Facial. Real Academia de Medicina y Cirugía de Valladolid. 1976.

8. Hipócrates. Tratados. Ed. Gredos. 2007. Barcelona.

9. Laín Entralgo P. Historia de la Medicina. Pág. 4. Salvat. Barcelona. 1978.

10. Lyons A.S., Petrucelli J.R. Historia de la Medicina. Edic. Doyma. Barcelona. 1984.

11. Pagel W. Paracelsus. An Introduction to Philosophical Medicine in the Era of

the Renaissance. Karger A.G. Basilea. München. 1982.
12. Plasschaert A. Perfil y competencias del odontólogo europeo. Asociación para la educación dental en Europa. Cardiff, 2004.

13. Ring M. Historia llustrada de la Odontología. Edic. Doyma. Barcelona. 1989

14. Tallmadge May M. Galen. On the Usefulness of the Parts of the Body. Cornell

University Press. New York. 1968. 